\title{
Explorando o potencial científico-social da coleção científica de fósseis do IGc/USP: preparação de material para pesquisa, exposição e uso didático
}

EXPLORING THE SCIENTIFIC AND SOCIAL POTENTIAL OF THE SCIENTIFIC FOSSIL COLLECTION OF IGC/USP: PREPARATION OF MATERIAL FOR RESEARCH, EXPOSURE AND DIDACTIC USE

\author{
Cibele G. Voltani ${ }^{1}$, Kelly B. V. Silva², Dayane G. Silva ${ }^{3}$, Regina H. R. C. Baptista ${ }^{3}$, Debora L. G. Lookin4, Thomas R. Fairchild ${ }^{5}$, Jullana M. Leme ${ }^{5}$ \\ 1- Programa de Pós-Graduação. Pós-Doutorado em Geociências, Univ. São Paulo. São Paulo, SP \\ 2- Programa de Pós-Graduação. Mestrado em Arqueologia. Museu de Arqueologia e Etnologia. Univ. São Paulo. São Paulo, SP \\ 3- Programa de Pós-Graduação. Mestrado Ensino e História de Ciências da Terra, Inst. Geoc. Unicamp. Campinas, SP \\ 4- Graduação. licenciatura em Geociências e Educação Ambiental, Inst. Geoc., Univ. São Paulo. São Paulo, SP \\ 5- Inst. Geoc., Univ. São Paulo. São Paulo, SP

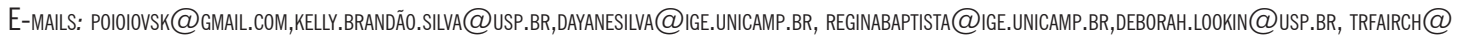 \\ HOTMAL.COM, LEME@USP.BR
}

Abstract: The Laboratory of Systematic Paleontology (LPS) of Institute of Geosciences (IGc) of University of São Paulo (USP) has one of the most valuable and varied paleontological collections in the Brazil. In 2012, the specimens from the actions to protect the fossiliferous heritage, passed permanently to IGc collection, making possible its use by researchers and the general public. Most of this material is composed of the Early Cretaceous fossils of the Araripe Basin in appreciable preservation conditions. However numerous specimens were adulterated to meet demand of illegal trade. These adulterations compromised the use of this material in scientific research, but did not compromise its use for education and scientific dissemination. LPS teachers have chosen to use this material to address scientific (e.g. major extinction events and types of fossilization) and social issues (e.g. scientific heritage and fossil smuggling). Issues related to paleontology, the development of the terrestrial system and the history of life on the planet are likely to contribute to the development of a global vision of the individual as a critical citizen. Through the actions presented here it is pointed out the relevance of the training trainees and the proximity of the teachers of the educational network with the researches of the university.

\section{Manuscrito:}

Recebido: Artigo selecionado, VIII Simpósio Nacional de Ensino e História de Ciências da Terra / EnsinoGE0-2018

Aceito: $11 / 12 / 2018$

Citation: Voltani, C. G., Silva, K. B. V. da, Silva, D. G. da,, Baptista, R. H. R. C., Gomes, D. L., Fairchild, T. R., \& Leme, J. M. 2019. Explorando o potencial científico-social da coleção científica de fósseis do IGc/USP: preparação de material para pesquisa, exposição e uso didático. Terræ Didatica, 15, 1-11. e019009. doi: 10.20396/td.v15i0.8654662

Keywords: paleontology, Geosciences education, continuing education for teachers, scientific dissemination.

\section{Introdução}

O Laboratório de Paleontologia Sistemática (LPS) do Instituto de Geociências (IGc) da Universidade de São Paulo, campus Capital (USP), possui uma das mais importantes coleções paleontológicas do Brasil, com amostras de diversas partes do mundo, contemplando todos os continentes. A partir da década de 1990, o LPS recebeu milhares de fósseis por doação; volume igual ou maior de material apreendido pela Polícia Federal (PF) e pelo Instituto de Patrimônio Histórico e Artístico Nacional (IPHAN) também foi entregue ao laboratório, sendo este o fiel depositário. Em 2012, este material, somando aproximadamente
10.000 espécimes, passou a pertencer ao IGc em definitivo, viabilizando seu estudo científico por parte de pesquisadores. Em 2013, foram recebidos mais 2.400 fósseis apreendidos pela PF, cuja maior parte diz respeito aos peixes fósseis do eocretáceo da Bacia do Araripe, com extraordinária preservação.

Entretanto, mais de um terço do total de peixes fósseis (3.392), consistem de Tharrhias e Rhacolepis, gêneros muito comuns, que frequentemente apresentam sinais de adulteração que comprometem seu valor científico (e.g. raspagem da morfologia original, colagem de peças de espécimes diferentes e entalhes na rocha simulando partes preservadas), com o intuito de tornar os espécimes mais parecidos com a imagem popular de "peixes".

\begin{tabular}{c|c}
\hline (C) Terrae Didat. & Campinas, SP \\
\hline
\end{tabular} 
Em 2013, por iniciativa do Prof. Thomas Rich Fairchild principiou-se o projeto "Explorando o potencial científico-social da Coleção Científica de Fósseis do IGc/USP: Preparação de material para pesquisa, exposição e uso didático", vinculado ao LPS do IGc, USP. O projeto foi premiado em $1^{\circ}$ Lugar na área de Ciências Exatas no $5^{\circ}$ Simpósio Aprender com Cultura e Extensão/USP, em 2016. O objetivo inicial foi proporcionar a aproximação dos alunos de graduação com a coleção científica e consequentemente extrapolar essa experiência para o público geral. Posteriormente, houve um avanço na concretização do curso para formação continuada dos professores da rede pública.

Desde então, cerca de onze estagiários participaram ativamente desenvolvendo as atividades propostas e apresentando os resultados parciais em simpósios, encontros científicos e congressos. O contato dos alunos de graduação com o LPS permite a vivência no cotidiano científico, experimentando métodos de investigação e das pesquisas paleontológicas. O projeto ainda incentiva a autonomia dos estagiários no desenvolvimento de materiais e recursos, como por exemplo, o guia para professor e a elaboração da exposição do material preparado quimicamente. Atualmente a orientação é realizada pela Prof. Dra. Juliana Leme, co-orientação da Dra. Cibele Gasparelo Voltani e coordenação de Ivone Cardoso Gonzales.

O projeto foca em diferentes frentes concomitantes, entre elas a (i) incorporação de exemplares na coleção científica, (ii) preparação mecânica e química de amostras de peixes fósseis, (iii) realização de exposição do material preparado, (iv) elaboração de uma técnica de baixo custo, que pudesse ser realizada em ambiente não controlado, para retirar as adulterações dos fósseis e a (v) formação continuada para professores da rede pública.

\section{Patrimônio paleontológico}

Os fósseis são considerados pela legislação brasileira bens da Nação (Decreto-lei no 4.146, 1942) e, portanto, não podem ser comercializados. Apesar das leis de proteção, o tráfico de fósseis movimenta um mercado milionário, e uma das áreas mais afetadas no Brasil é a região da Chapada do Araripe, no sertão nordestino.

A educação patrimonial é uma das estratégias para o combate ao tráfico e fortalecimento das comunidades próximas aos sítios paleontológicos. Alguns trabalhos voltados para os educadores da região foram realizados pela Universidade Federal de Pernambuco e pelo Departamento Nacional de Produção Mineral (DNPM) regional.

A utilização do material recebido de apreensões da PF e do IPHAN é uma importante oportunidade de aproximar a paleontologia das escolas, proporcionar o contato do público externo à universidade com esse material tão raro, além de navegar de forma transversal entre os temas tratados na educação formal.

\section{Paleontologia e educação}

A paleontologia tem um caráter integrador, em que diversos ramos do conhecimento científico interagem para compreender as dinâmicas da vida pretérita na Terra; os resultados podem ser de interesse geral da população e muitas vezes associados com a vida cotidiana (Mello, Mello \& Torello, 2005). Desta forma, a divulgação da paleontologia colabora na compreensão sistêmica do mundo, reforça a importância da preservação do patrimônio natural e geológico, e contribui para uma formação cidadã.

O conhecimento paleontológico embora importante para a compreensão da história e evolução do planeta, ainda é pouco implementado ou, às vezes, inexplorado na educação básica brasileira. Nos Parâmetros Curriculares Nacionais (PCN's) (Ministério da Educação, Secretaria de Educação Fundamental, 1998) a paleontologia não consta como conteúdo conceitual, aparece de forma fragmentada e transversal nas disciplinas de ciências naturais, biologia e geografia.

No ensino básico, os temas paleontológicos, quando abordados, são habitualmente trabalhados com base em informações retiradas da mídia, contendo muitas vezes erros conceituais, o que é apontado por pesquisas de Nobre (2014) e Schwanke \& Silva (2010). Estas últimas, por sua vez, também chamam a atenção para o fato de que no Brasil o conhecimento paleontológico está restrito a instituições ligadas a pesquisa, como museus ou empresas petrolíferas, não alcançando a sociedade e principalmente, os espaços educacionais.

Nobre (2014) ressalta a preocupação da diferença e distanciamento existente entre as pesquisas científicas na área paleontológica e o conteúdo apresentado na área de ensino. A autora reforça a relevância dos conceitos paleontológicos para uma melhor compreensão das questões geoló- 
gicas, biológicas e ambientais, e assim justifica a incorporação destes conceitos nos currículos da educação básica.

Nos últimos anos ocorreram avanços na criação de espaços para abordagem de educação em Paleontologia em encontros regionais. Como exemplo, a Paleo SP, que desde 2013 realiza a "Paleo para Todos”, um espaço para divulgação, discussão e acesso da população a essa área do conhecimento, e os simpósios de Educação em Paleontologia, dentro dos Congressos Brasileiros de Paleontologia.

A realização de cursos e parcerias entre universidades, laboratórios, museus e escolas em todo Brasil, apesar de pontual, tem aproximado o conhecimento acadêmico do ensino básico; e com essa finalidade o projeto, cujos resultados apresentamos aqui, foi desenvolvido.

\section{Objetivos}

Como objetivo, utilizamos o potencial da coleção científica para promover a Paleontologia tal qual ferramenta educacional em duas vertentes principais: para o público interno da universidade, colaborando para sua formação acadêmica, e para o público externo, representado pela formação continuada de professores da rede pública.

Como objetivos específicos, temos:

- Participação dos estagiários do LPS (IGc, USP) no registro de documentação digital dos espécimes-tipo e ilustrados em publicações;

- Treinamento dos estagiários para reconhecimento de elementos osteológicos diagnósticos dos espécimes mais comuns dos peixes fósseis (paleoictiofauna) da Formação Santana (de idade eocretácica, Bacia do Araripe);

- Preparação mecânica e química de exemplares representativos das espécies mais comuns da paleoictiofauna da Bacia do Araripe;

- Estabelecimento de uma técnica de baixo custo para a recuperação dos fósseis visando a sua utilização em escolas públicas;

- Desenvolvimento de um guia para professores;

- Preparação de kits com material fóssil e guia para professores;

- Desenvolvimento e realização do curso de formação continuada voltada para professores da rede pública de ensino.

\section{Materiais e métodos}

\subsection{Preparação de material para pesquisa}

\subsubsection{Incorporação dos fósseis na coleção científica}

O processo de curadoria compreende catalogar, preparar, identificar e acondicionar o material paleontológico (Goellner \& Malabarba, 2010). A informatização e digitalização dos dados contidos no acervo para a disponibilização "on line", ocorre através do programa LUND, criado por pesquisadores, programadores e alunos da UNESP, em Bauru (Ghilardi, Soler \& Langer, 2012). Os dados ficam disponíveis via servidor da UNESP, em Bau$\mathrm{ru}$, que concentra as informações sobre coleções paleontológicas brasileiras.

Os estagiários fazem o processo de catalogação e digitação das informações taxonômicas, idade e localização do material da coleção científica de vertebrados para o banco de dados do programa LUND, além do processo de acondicionamento do material de forma adequada nos módulos de estantes deslizantes.

\subsubsection{Curso sobre osteologia e aspectos teóricos da preparação química}

O curso consiste na apresentação de conceitos básicos sobre bacias sedimentares, taxonomia, fósseis, fossilização e preparação química.

Com a abordagem de bacias sedimentares, o intuito foi introduzir os participantes ao contexto geológico da Bacia do Araripe, mais especificamente em uma de suas formações, a Formação Santana (Assine, 2007), de cujos sedimentos provêm a paleoictiofauna utilizada. Também foram abordados modelos propostos de fossilização para o caso específico da Formação Santana (Martill, 1988; Martill, 1989; Maisey, 1991a). Posteriormente, foram tratadas as etapas de preparação química (adequadas de Toombs \& Rixon 1959), os materiais necessários e os cuidados com a segurança pessoal para o manuseio da solução ácida.

Finalmente foram fornecidos conceitos acerca da taxonomia e quais elementos compreendem a diagnose de uma espécie e as diferenças, no que diz respeito, à espécie de um organismo atual e de um organismo fóssil (Papavero, 1994). E, por último, apresentados os elementos osteológicos diagnósticos para a paleoictiofauna da Bacia do Araripe, com a utilização dos fósseis, em aula prática. 
Para cada peixe abordado, foi utilizada uma ficha com dois esquemas, um morfológico do peixe completo e outro com os elementos cranianos detalhados (modificados de Forey, 1977; Maisey, 1991b; Grande \& Bemis, 1998). Então, com o peixe fóssil e esquema em mãos, os alunos foram convidados a (i) pintar, no esquema, as estruturas osteológicas que eram reconhecíveis nos fósseis, e depois as outras estruturas osteológicas cranianas não identificáveis no fóssil, de modo a observar e entender suas relações topográficas, em esquema. Assim, os alunos estagiários adquiriram vocabulário específico sobre a morfologia dos peixes e tornaram-se aptos a identificar elementos básicos para reconhecimento dos gêneros fósseis.

\subsubsection{Preparação mecânica e química dos peixes}

Para expor estruturas ósseas dos peixes fósseis de forma detalhada, permitindo seu estudo com precisão, utilizam-se técnicas de preparação mecânica e química.

A decisão entre utilizar a técnica mecânica ou química varia, dependendo do objetivo final e da condição de preservação de cada fóssil; pode ocorrer o uso da combinação das técnicas para um melhor resultado.

A preparação mecânica geralmente é mais trabalhosa, o acesso à região interna das estruturas ósseas frequentemente não é satisfatório e nem sempre evita avarias nas estruturas ósseas. Para este tipo de preparação são utilizados pincéis, estilete histológico e microrretífica. A preparação mecânica visa a retirada de maior parte do sedimento, de modo a deixar a face do fóssil, que já está exposta, com a melhor resolução possível.

O processo químico constitui diversos ciclos de imersão em solução ácida para dissolver a matriz e expor os ossos. Este método de preparação (adequado de Toombs \& Rixon, 1959) consiste em pri- meiramente resinar a parte visível do fóssil com o objetivo de preservá-lo. É feita uma cama de massa de modelar no entorno do fóssil, em seguida uma parede de proteção com papelão ondulado ou placa de acetato e, posteriormente, cobre-se o fóssil utilizado uma mistura de resina poliéster transparente, monômero de estireno e butanox. Após 24 horas, com a resina já seca é possível iniciar a imersão em solução ácida.

O ácido utilizado foi o acético glacial, que reage com o carbonato de cálcio sem afetar excessivamente o fosfato de cálcio dos ossos. Inicia-se então uma sequência de ciclos de três etapas: (1) É realizada a imersão do fóssil resinado num recipiente com solução de ácido acético glacial a 5\%, cálcio trifosfático e água por 24 horas; (2) Nas 24 horas seguintes o fóssil fica imerso na água para neutralizar o ácido; (3) Nas 24 horas posteriores espera-se o fóssil secar. Este procedimento é repetido até que haja exposição das estruturas ósseas de forma satisfatória. Caso necessário, no fim de cada ciclo é possível aplicar um consolidante, geralmente um paraloide, que consiste de base translúcida de resina acrílica, para ajudar a preservar as estruturas ósseas tanto nas imersões futuras, quanto para posterior acondicionamento / exposição.

\subsection{Preparação e elaboração de material didático}

\subsubsection{Desenvolvimento de um método de baixo custo para dissolução do sedimento}

Por intermédio de experimentos e testes foi desenvolvido procedimento, para dissolução do sedimento carbonático, de baixo custo, não tóxico (Fig. 1) e possível de utilizar em escolas, inclusive com crianças. O objetivo final consistiu em retirar a matriz de forma segura expondo o fóssil e/ou removendo as adulterações.
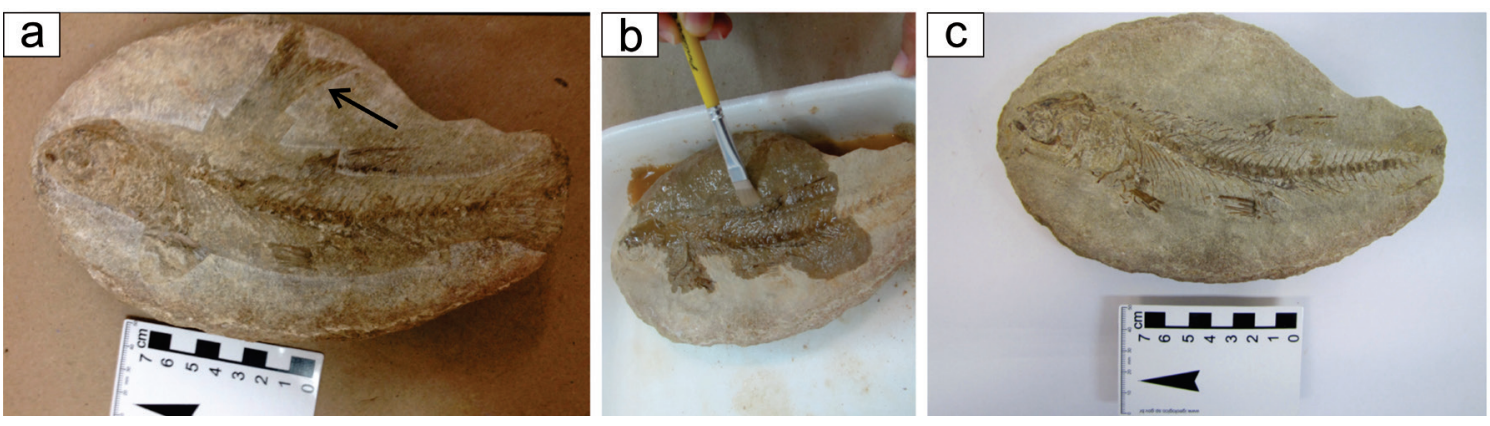

Figura 1. (a) Concreção contendo um peixe fóssil. A seta indica a nadadeira caudal de um segundo espécime na mesma concreção. (b) aplicação de vinagre, com pincel, sobre o peixe fóssil com adulterações. (c) Notar que a nadadeira caudal apontada pela seta em (a) foi eliminada e as estruturas osteológicas agora se encontram livres de contornos forjados 
Diversos materiais ácidos foram cogitados inicialmente, como por exemplo, as frutas cítricas e refrigerantes a base de cola, porém o vinagre apresentou a melhor relação custo-benefício. Foram realizados testes com vinagres de entre $4 \%$ e $6 \%$ de concentração de ácido acético e não houve diferenças significativas entre eles, em relação ao tempo de ação na rocha.

O método baseado nas práticas de laboratório com imersão em vinagre por 24 horas, seguida de imersão em água por 24 horas e secagem não apresentou bons resultados para o objetivo. Neste caso, o mais funcional foi trabalhar com as áreas de interesse de forma isolada, utilizando pincel ou algodão embebido em vinagre.

Os passos sugeridos para a retirada das adulterações nos fósseis foram:

- Identificar as áreas adulteradas;

- Aplicar vinagre, com um pincel de cerdas médias, esfregando a área específica, ou embeber um pedaço de algodão em vinagre e colocar sobre a área escolhida;

- Lavar com água e deixar secar até a próxima aplicação;

- Repetir as aplicações até obter o resultado esperado.

Desta forma, a aplicação é pontual e os resultados mais rápidos e visíveis; o vinagre dilui o sedimento carbonático de forma lenta, e é possível retirar as adulterações sem causar grandes impactos macroscópicos ao fóssil.

\subsubsection{Elaboração do guia para professores}

A elaboração do guia paleontológico para professores foi realizada de forma colaborativa entre os estagiários e orientadores. A partir das primeiras leituras propostas, foram sugeridos pelos alunos temas para compor o guia. O passo seguinte foi o aprofundamento das pesquisas bibliográficas resultando na redação do primeiro esboço.

Os temas foram divididos entre os alunos e a ordem, conteúdos e redação dos temas até a finalização do guia discutidos em reuniões periódicas.

O guia para o professor foi desenvolvido com o propósito de auxiliá-lo durante o manuseio do fóssil, quando em sala de aula, com linguagem acessível e imagens explicativas. Além do propósito primeiro, o guia também exerceu papel de suporte durante o curso de formação continuada para os professores da rede pública. Os temas partiram da reflexão que a paleontologia é um dos caminhos para compreender a dinâmica do Sistema Terra, as mudanças ambientais, questões sobre a preservação do patrimônio natural, além de colaborar para a formação do cidadão consciente do seu meio.

Os temas tratados, em ordem, foram:

- A construção da história da vida, abordando o que é a paleontologia, o que são os fósseis e como eles ocorrem, o tempo geológico, as datações absoluta e relativa e os grandes eventos de extinção.

- O processo de fossilização, bioestratinomia, diagênese e os diferentes tipos de fossilização;

- A Bacia do Araripe, as características regionais de fossilização, os grupos de peixes da região, legislação e o tráfico de fósseis.

- Sugestão de um método para preparação do peixe fóssil.

- Ficha técnica do fóssil distribuída para as escolas.

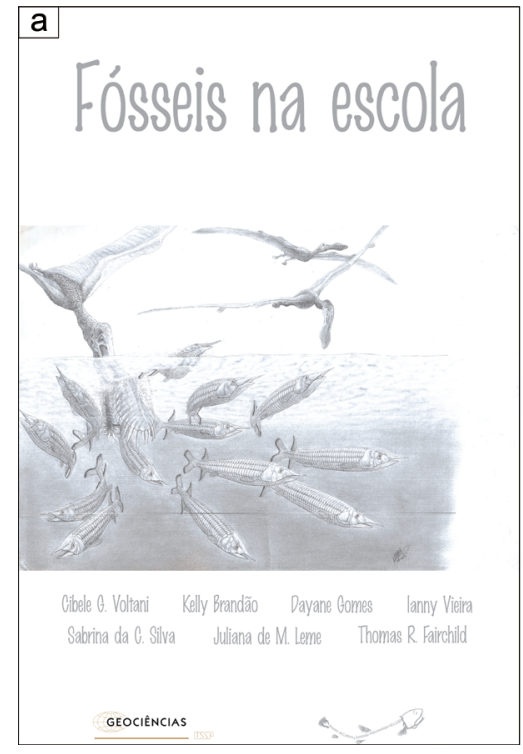

b

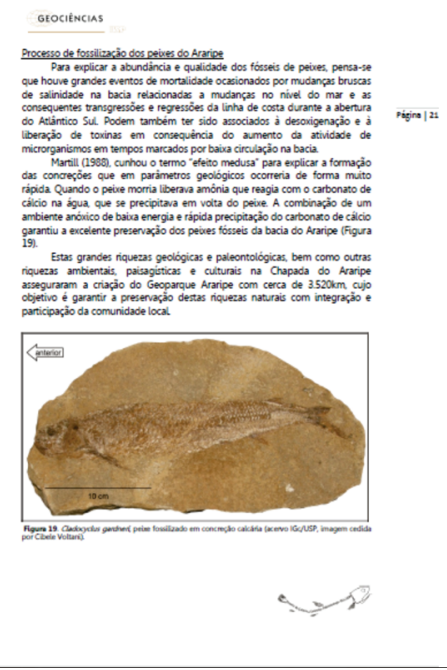

Figura 2. Imagens do guia elaborado para o curso de formação continuada para os professores. Em (a) a capa do guia. (b) uma das páginas internas do guia, contendo imagem de outro peixe fóssil da Bacia do Araripe, Formação Santana 
O guia (Figura 2), com aproximadamente 40 páginas, foi a base para a preparação do curso de formação continuada para professores.

\subsection{Curso de formação continuada de professores}

O curso de formação continuada e aprimoramento para os professores na área de paleontologia deu-se em parceria com o projeto USP ESCOLA, um programa que oferece gratuitamente cursos para docentes de diversas disciplinas do ensino médio. Esta parceria possibilitou maior dedicação para o preparo e organização das atividades. O curso de Paleontologia teve duração de uma semana e foi estruturado da seguinte forma:

- A construção da história da Terra, Tempo Geológico: aulas expositivas dialogadas e práticas com amostras;

- Conceitos de Paleontologia e fósseis: aulas expositivas dialogadas e práticas com fósseis;

- Processo de fossilização e ocorrência dos fósseis: aulas expositivas dialogadas e atividade prática de tipos de fossilização;

- Bacia do Araripe e fossilização dos peixes: Aulas expositivas dialogadas e práticas com fósseis;

- Gestão do Patrimônio fossilífero brasileiro e o tráfico de fósseis: aula expositiva dialogada, recursos de vídeo;

- Aplicação da Paleontologia nas diferentes áreas da ciência: Aulas expositivas dialogadas;

- Preparação de um fóssil: aula prática;

- Visita guiada ao Museu de Geociências e Oficina de Réplicas (IGc/USP).

Ainda durante a semana do curso ocorreram duas palestras: uma sobre dinossauros brasileiros e outra sobre palinologia forense, com vistas à integração de outros professores de paleontologia do IGc, bem como dos alunos de pós-graduação. Também foi realizada visita monitorada ao Museu de Geociências e à coleção científica, com apresentação de atividades desenvolvidas por outros alunos estagiários e por funcionários da instituição supracitada. O contato com outros profissionais da área, bem como a visita a outros espaços físicos do IGc, teve como intenção a abertura de importantes canais, para que o professor que frequentou o curso sinta-se à vontade para revisitar o instituto com seus alunos.

Buscou-se desenvolver atividades participativas, respeitando e agregando o conhecimento trazido pelos professores. Considerando as orientações de Carvalho \& Gil-Pérez (2011), para que os professores sejam ativos na construção do seu próprio conhecimento, as propostas de atividades didáticas não devem ser apresentadas já concluídas e, portanto, devem propiciar uma "mudança didática". Essas ações devem conduzir os professores, a partir de seus próprios conhecimentos e concepções, a desenvolver seus recursos e refletir sobre suas ideias e ações em relação a sua prática de ensino (Carvalho, 2004).

O curso foi um importante passo para aproximar o material paleontológico e conceitos básicos com os profissionais da educação. Os dados obtidos prosseguem sendo coletados e analisados. Durante a semana de execução foram aplicados questionários qualitativos e quantitativos para os professores, além da troca de contatos para a realização do acompanhamento de atividades futuras com o material disponibilizado. O objetivo é a produção de dados que possibilite melhorar e compreender as dificuldades com as quais os docentes se depararam e, a partir de críticas, aperfeiçoar próximas edições do curso.

\subsection{Leituras orientadas}

De acordo com Freitas (1992, p. 96), "a questão não é aumentar a prática em detrimento da teoria, nem a teoria em detrimento da prática. A ideia é adotar uma nova forma de produzir conhecimento, pois a teoria e a prática" se complementam. Andrade \& Longarezi (2007) examinam o ensino como atividade que necessita de conhecimentos específicos e sólidos por formação dedicada a esta finalidade.

Assim, as leituras são realizadas durante as horas de estágio, por serem compreendidas como parte importante no projeto, possibilitando a formação e desenvolvimento acadêmico dos estagiários. Os textos propostos tiveram dois focos: (1) os conceitos geológicos de bacias sedimentares, a caracterização da Bacia do Araripe, suas formações geológicas e os peixes fósseis da região e, mais recentemente, (2) a incorporação de artigos científicos voltados para a educação e divulgação em geociências, com vistas à paleontologia e a formação continuada para professores. 

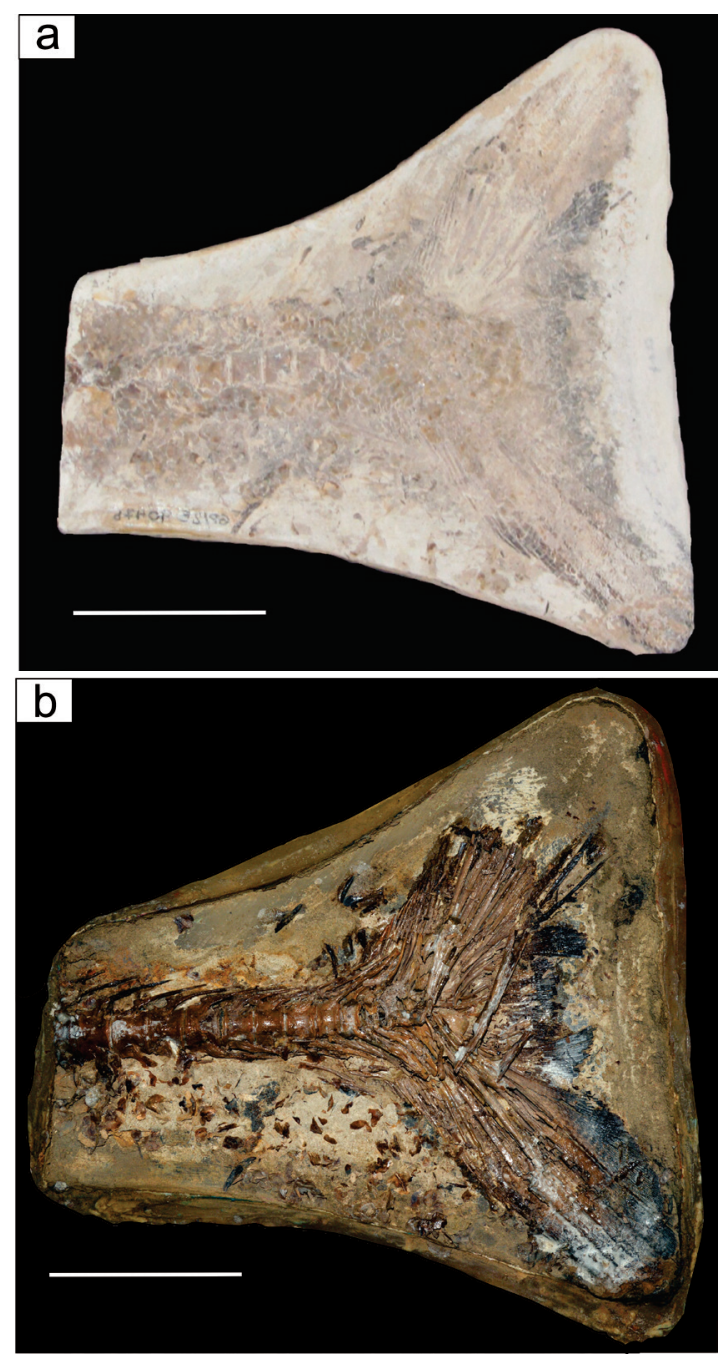

Figura 3. (a) Terço posterior da coluna vertebral de um peixe fóssil com raios de nadadeira caudal, antes da preparação química com ácido acético glacial. (b) a mesma peça fóssil após preparação química

\section{Resultados e discussão}

\subsection{Preparação do material para pesquisa}

O contato com material fóssil, conservação e documentação digital proporciona aos estagiários valiosa aprendizagem em Paleontologia e no funcionamento de coleções científicas. No decorrer do projeto as incorporações realizadas para novos exemplares provenientes de doações e apreensões, além da inserção da coleção de vertebrados no sistema de software livre LUND, permitiram a consolidação e disponibilização do banco de dados para pesquisadores e interessados em geral de qualquer parte do mundo.

\subsubsection{Resultados da preparação mecânica e química}

Foram preparadas (Figs. 3 e 4) 12 amostras de fósseis buscando contemplar a variação de exemplares existentes na coleção científica. Os fósseis que receberam tratamento mecânico foram Iansan beurleni e a parte anterior de Calamopleurus cylindricus. Aqueles tratados quimicamente foram Brannerion latum, parte posterior de Calamopleurus cylindricus, Cladocyclus sp., Iansan beurleni, parte inferior de Mawsonia gigas, Neoproscinetes penalvai, Notelops brama, parte posterior de Paraeolops cearensis, Rhacolepis sp., Tharrhias araripis, Vinctifer sp. e um peixe indeterminado.

O preparo do material fóssil com a fundamentação teórica obtida durante o curso de osteologia deu aos alunos conhecimentos e ferramentas para que pudessem elaborar uma exposição com esse material.

Figura 4. Preparação mecânica de amostra de peixe fóssil. (a) Utilização da microrretífica, sob esteromicroscópio, para remoção de sedimentos próximos às estruturas ósseas. (b) utilização de esmerilhadeira para remoção da maior parte de sedimento, na face onde o fóssil ainda não estava visível. Esta remoção diminui o tempo de ação durante a preparação química. (c) Exemplar de lansan beurleni, uma raia fóssil, que passou por preparação mecânica
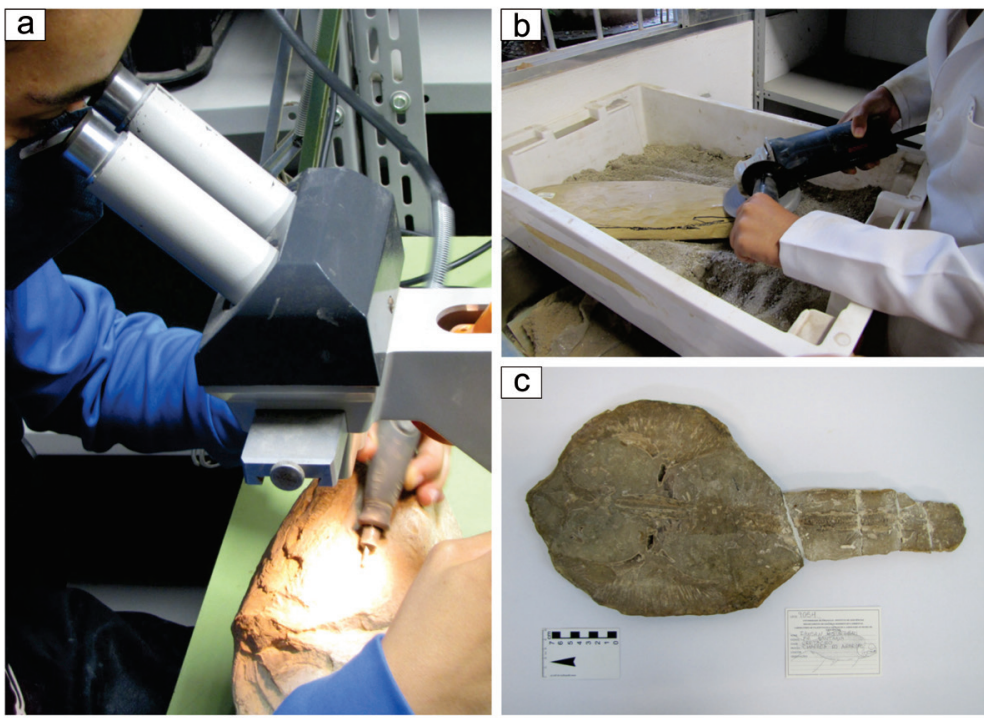


\subsubsection{Elaboração da Exposição em parceria com 0 Museu de Geociências IGc, USP}

A exposição no Museu de Geociências (Fig. 5) foi planejada e realizada pelos alunos de graduação, com a colaboração dos funcionários do Museu de Geociências IGc, USP e orientação dos professores responsáveis pelo projeto. O objetivo da exposição foi mostrar ao público parte do trabalho desenvolvido pelos estudantes, proporcionar a prática do processo mecânico de retirada de sedimentos com o auxílio do estereomicroscópio e instrumentos de mão, os quais foram disponibilizados no dia da inauguração da exposição, e exibir os diferentes tipos de espécimes de peixes fósseis que o acervo do IGc dispõe.

A preparação da exposição consistiu em apresentar os dados cientificos com uma linguagem e disposição acessível ao público geral e, para isso, foram criadas etiquetas de identificação para cada morfótipo com: o nome do fóssil, a estratigrafia, local e idade. Além disso, foram expostos pôsteres indicando a região de origem, os aspectos da bacia sedimentar do Araripe, os passos para a preparação física e química dos fósseis até o resultado satisfatório e esquemas das partes duras (esqueléticas) que foram expostas após a realização dos processos.

A exposição ficou disponível para o público por cinco meses e está sendo reavaliada para tornar-se permanente no espaço do IGc, USP.

\subsection{Preparação e elaboração de material didático}

\subsubsection{Elaboração de kit com material fóssil}

O kit compreende um conjunto de objetos, cuja escolha visa aperfeiçoar a experiência do professor e consequentemente dos alunos em sala de aula. Compõem o kit: (1) um guia intitulado "Fósseis na escola" (para conteúdo vide item 5.2.2); (2) um fóssil de Tharrhias araripis com marcas de adulteração; (3) um banner com informações resumidas sobre a Bacia do Araripe, escala de tempo geológico, morfologia de T. araripis e imagens dos resultados obtidos pelos alunos estagiários, referentes à preparação do peixe fóssil com o vinagre; (4) um pincel para que o vinagre seja aplicado no fóssil, segundo indicações contidas no guia.

T. araripis foi o peixe fóssil escolhido para integrar o kit por duas razões: abundância na coleção científica e frequentes marcas de adulteração, como entalhes na rocha, alterando a morfologia original

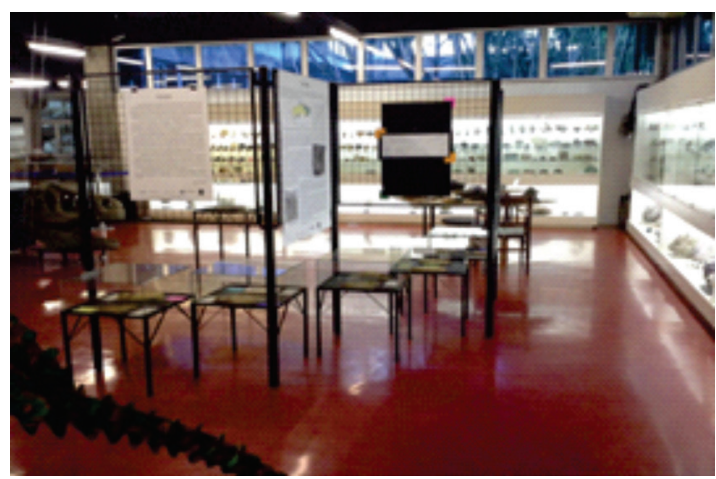

Figura 5. Exposição no Museu de Geociências, IGc, USP, idealizada e organizada pelos estagiários do projeto

do fóssil ou de seus restos. Felizmente, as concreções portando T. araripis comumente apresentam restos de mais de um indivíduo, de modo que há chance de encontrar mais estruturas osteológicas.

Os fósseis foram entregues às escolas em função da participação dos docentes no curso de formação continuada e mediante o preenchimento de um termo de permissão de uso, um acordo oficial e válido entre o IGc, USP e a instituição de ensino. A escola será, a partir do momento em que assina o termo, a responsável legal pelo fóssil, responsável por sua guarda e utilização para fins educativos.

\subsection{Curso de formação continuada de professores}

As avaliações da formação continuada para professores mostraram algumas diretrizes para o aperfeiçoamento da segunda edição do curso. Para avaliação das atividades foram elaborados questionários com perguntas fechadas, que eram respondidas ao fim de cada dia. Ao final do curso aplicou-se um questionário com perguntas abertas e, após seis meses, foi solicitado por e-mail relatos de atividades realizadas pelos professores, inspiradas no curso em questão. Os resultados ainda estão sendo processados; aqui serão apresentados os dados dos questionários com perguntas fechadas (Fig. 6).

De forma geral o curso obteve uma ótima avaliação, porém alguns pontos como atividades práticas, qualidade do material didático disponibilizado e utilização do tempo de aula disponível apresentaram alguns pontos como regular nas aulas 3 e 4 mostrando que estas precisam de melhorias.

\subsection{Considerações}

Os graduandos que participaram deste projeto vieram dos cursos de Geologia (IGc, USP), Licenciatura em Geociências e Educação Ambiental (IGc,

\begin{tabular}{c|c|c|c|c|c|}
\hline (c) Terrae Didat. & Campinas, SP & v.15 & $1-11$ & $\mathrm{e} 019009$ & 2019 \\
\hline \multicolumn{2}{c}{8}
\end{tabular}



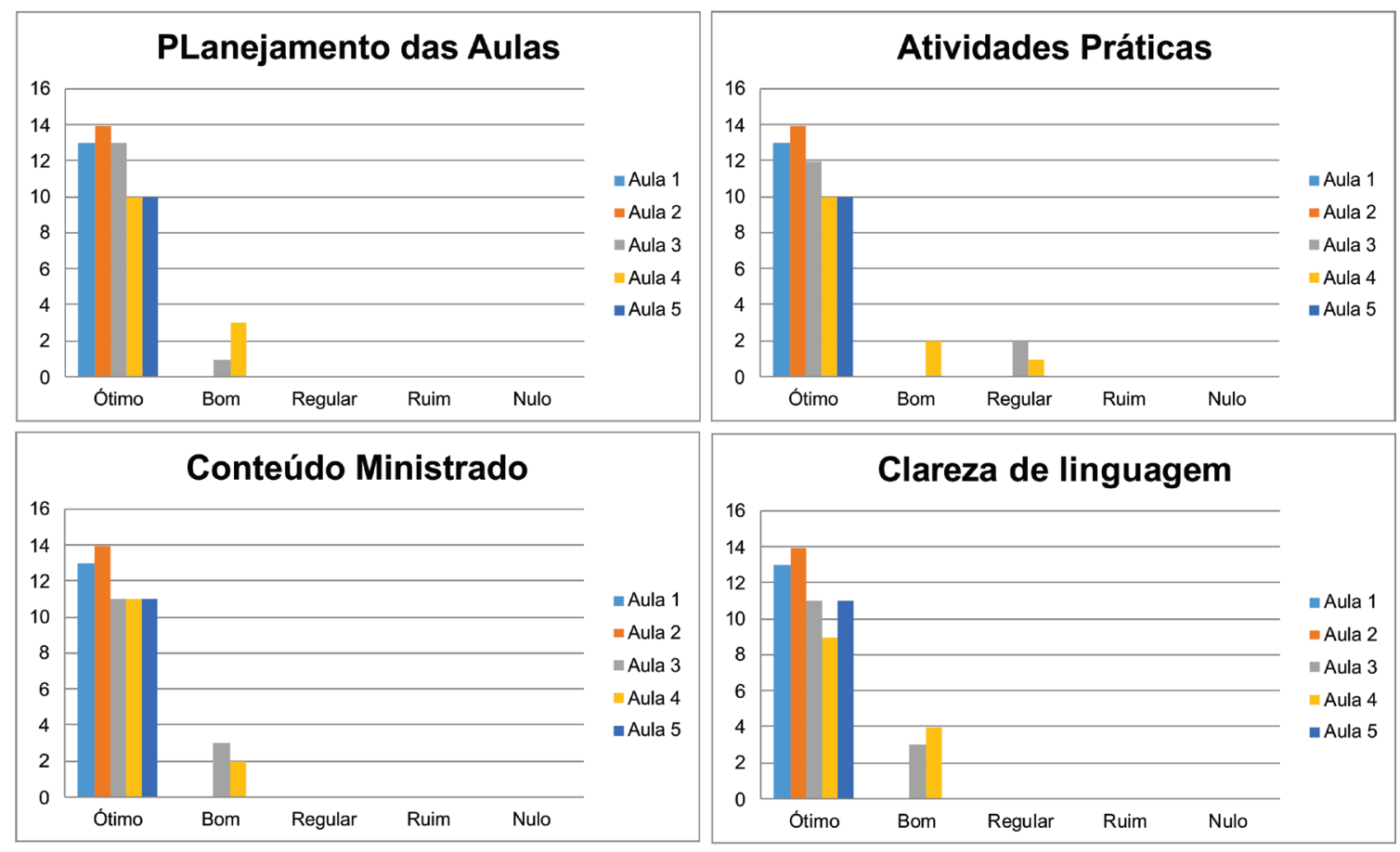

Qualidade do material didático disponibilizado

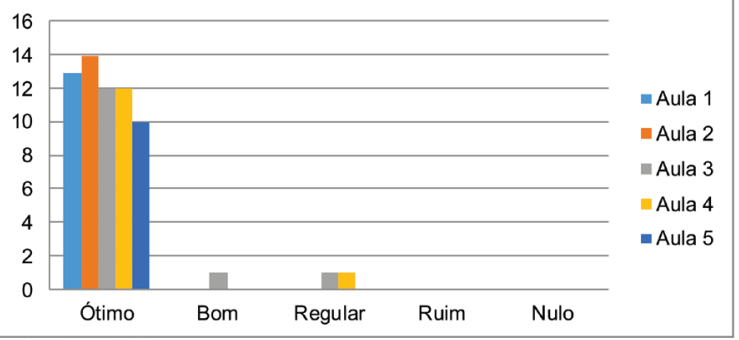

Utilização do tempo de aula disponível

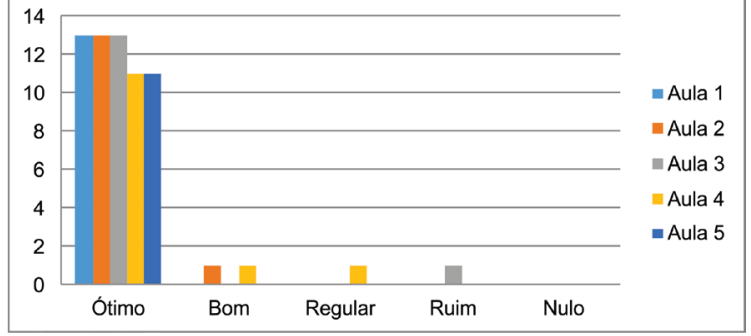

Figura 6. Gráficos dos principais pontos analisados no curso, mostrando sua classificação por aula

USP) e Licenciatura em Ciências (EACH, USP). A paleontologia é abordada em algum momento destes cursos, porém para um bom aproveitamento durante o período de estágio foram elaboradas estratégias didáticas com o intuito de aprofundar alguns conceitos, potencializar o trabalho coletivo e fortalecer a autonomia das atividades e recursos desenvolvidos por eles.

O estágio é um momento importante de experimentação, que pode revelar vários aspectos do cotidiano profissional. Pode representar a consolidação do comprometimento ou pode ser o momento da renúncia (Pataca, et al., 2011). A orientação sistemática, em forma de reuniões, cursos e atividades práticas buscaram de forma gradual cumprir o calendário estabelecido, debater os diversos temas e sanar dúvidas, além de discutir as perspectivas futuras do projeto. O projeto permitiu aos doze alunos de graduação que participaram até o momento, pelo período mínimo de um e máximo dois anos, o recebimento de bolsas fomentadas pela USP, sendo importante ressaltar que essas bolsas, além de manter o projeto em funcionamento, colaboraram com a permanência do estudante na universidade.

As dez horas semanais do estágio foram fracionadas abrangendo diferentes etapas e garantindo o desenvolvimento do projeto em todas as vertentes.

Durante toda a experiência do aluno no LPS do IGc/USP foi incentivada a participação em eventos científicos. É uma forma de aproximar o estudante das pesquisas atuais, participar de debates, conhecer pesquisadores de outras instituições, exercitar a elaboração de trabalhos científicos e adquirir experiência com apresentações e questionamentos nesses espaços.

\begin{tabular}{c|c|c|c|c|c}
\hline C Terrae Didat. & Campinas, SP & v.15 & n.1 & e019009 & 2019 \\
\hline \multicolumn{2}{|c}{9}
\end{tabular}




\section{Conclusões}

Ultrapassar os muros da universidade não é uma tarefa fácil; além de enfrentar dificuldades como baixo orçamento, burocracias e pouco incentivo para trabalhos de extensão, há o desafio em traduzir, para uma linguagem acessível, as pesquisas, ou parte delas, realizadas na academia. Compartilhar o material e o conhecimento científico do LPS era uma demanda antiga e que se concretizou com o desenvolvimento deste projeto. São muitos os fósseis, disponíveis na coleção, com marcas de adulterações (para atender o comércio ilegal), que diminuem seu valor científico. Utilizar esse material para fins didáticos é um caminho justo, que colabora com a divulgação e permite a discussão sobre preservação do patrimônio paleontológico brasileiro, além da ampliação ao acesso deste tipo de material.

A formação dos estagiários foi um foco importante no projeto, uma boa formação e contato com os conhecimentos científicos podem ser determinantes na escolha por seguir na área de pesquisa. Buscamos trazer o aluno de graduação para as atividades cotidianas do laboratório e estimular o exercício de autoria, como a criação de atividades, a discussão do andamento e o planejamento do futuro para o projeto. $\mathrm{O}$ amadurecimento do aluno como profissional ocorre de forma gradual e são os estágios orientados que possibilitam a vivência prática, o acúmulo de experiências, o exercício da autonomia e desenvolvimento de segurança para tomadas de decisões. Por outro lado, o aluno de graduação, aqui no papel de estagiário, é o coração do projeto, sem sua participação seria praticamente impossível o andamento e ampliação das atividades com o público externo à universidade.

Outro foco importante foi à formação continuada para professores, que ocorreu com a oferta do curso para professores da rede pública de ensino. Até o momento foi realizada uma edição, embora exista a expectativa de que ocorra pelo menos uma vez por ano, e que haja um acompanhamento sistemático junto com as escolas do uso do material cedido. Foram aplicados questionários para a avaliação qualitativa e quantitativa do curso que permitiram observar algumas percepções dos participantes. O resultado está colaborando para o aperfeiçoamento de futuras edições, além de possibilitar a autocrítica da equipe organizadora.

\section{Referências}

Andrade, R. C., \& Longarezi, A. M. (2007). Estágio Supervisionado na Formação de Professores: A Relação Teoria e Prática. In Anais do Encontro de Pesquisa em Educação e Congresso Internacional de Trabalho Docente e Processos Educativos. Proceedings of the $6^{\text {th }}$ Congress of the Universidade de Uberaba (pp. 1) Uberaba, Brazil.

Assine, M. L. (2007). Bacia do Araripe. Boletim de Geociências da PETROBRAS, 15(2), 371-389.

Carvalho, A. M. P., \& Gil-Pérez, D. (2011). Formação de professores de ciências: tendências e inovações. ( $1^{\text {st }} \mathrm{ed}$.). São Paulo, Brazil: Cortez.

Carvalho, A. M. P. (Org.). (2004). Ensino de Ciências-unindo a pesquisa e a prática (1 $1^{\text {st }}$ ed.). São Paulo, Brazil: Cengage Learning Editores.

Decreto-lei n 4.146, 1942 (1942, March 04). Recuperado de: http://www2.camara.leg.br/legin/fed/declei/1940-1949/decreto-lei-4146-4-marco-1942-414164-publicacaooriginal-1-pe.html

Forey, P. L. (1977). The Osteology of Notelops, Woodward, Rhacolepis Agassiz and Pachyrhizodus Dixon (Pisces: Teleostei). British Museum (Natural History), 24, 125-204.

Freitas, L. C. (1992). Neotecnicismo e formação do educador. In N. Alves (Org.). Formação de professores: pensar e fazer. ( $7^{\text {th }}$ ed., pp. 89-102). São Paulo, Brazil: Editora Cortez.

Goellner, L. L., \& Malabarba, M. C. S. L. (2010). Curadoria e preparação de fósseis no Laboratório de $\mathrm{Pa}-$ leontologia do MCT-PUCRS. In Salão de Iniciação Cientifica. Proceedings of the $11^{\text {th }}$ Conference of the graduate students of the Pontifícia Universidade Católica (pp. 313-315). Rio Grande do Sul, Brazil.

Ghilardi, R.P, Soler, M.G., Langer, M.C. (2012) LUND: uma proposta de base de dados de coleções paleontológicas brasileiras. In M. H. Henriques, A. I. Andrade, M. L. Quinta-Ferreira, F. C. Lopes, M. T. Barata, R. Pena dos Reis \& A. Machado (Coords). Para Aprender com a Terra: Memórias e Notícias de Geociências no Espaço Lusófono. (1 ${ }^{\text {st }}$ ed., pp. 1-6). Coimbra, Portugal: Imprensa da Universidade de Coimbra.

Grande, L., \& Bemis, W. E. (1998). A comprehensive phylogenetic study of amiid fishes (Amiidae) based on comparative skeletal anatomy. An empirical search for interconnected patterns of natural history. Journal of Vertebrate Paleontology, 18(S1), 1-696.

Maisey, J .G. (1991a). Fossil forensics. In J. G. Maisey (Ed.), Santana fossils, an illustrated Atlas (1 ${ }^{\text {st }} \mathrm{ed}$., pp. 57-89).Neptune City, NJ: TFH Publications Incorporated.

Maisey, J. G. (1991b). Systematic Atlas: Fishes. In J. G. Maisey (Ed.), Santana fossils, an illustrated Atlas (1 ${ }^{\text {st }}$ ed., pp. 258-271). Neptune City, NJ: TFH Publi- 
cations Incorporated.

Martill, D. M. (1988). Preservation Of Fish In The Cretaceous Santana Formation Of Brazil. Palaeontology, 31(1), 1-18.

Martill, D. M. (1989). The Medusa effect: instantaneous fossilization. Geology Today, 5(6), 201-205.

Mello, F. T., Mello, L. H. C., \& Torello, M. B. F. (2005). A Paleontologia na Educação Infantil: alfabetizando e construindo o conhecimento. Bauru: Ciência E Educação, 11(3).

Ministério da Educação, Secretaria de Educação Fundamental. (1998). Parâmetros curriculares nacionais: Ciências Naturais. Secretaria de Educação Fundamental. Recuperado de http://portal.mec.gov.br/ seb/arquivos/pdf/ciencias.pdf.

Nobre, S. B. (2015). Paleontologia e Palinologia na Formação de Professores: Perspectivas e Estratégias para o Ensi- no de Ciências e Biologia na Educação Básica Recuperado de http://www.ppgecim. ulbra.br/teses/index. php/ppgecim/article/ view/201/196.

Papavero, N. (Org.). (1994). Fundamentos práticos de taxonomia zoológica: coleções, bibliografia, nomenclatura ( $2^{\text {nd }}$ ed.). São Paulo, Brazil: Unesp.

Pataca, E., Melo, N. P., Magalhães E., \& Ifanger, L. A. C. N. (2011). Relatos autobiográficos na formação inicial de professores em Geociências e Educação Ambiental. Poieses Pedagogica, 9(1), 162-178.

Schwanke, C., \& Silva M. A. J. (2010). Educação e Paleontologia. In I. S. Carvalho (Ed.). Paleontologia. ( $3^{\text {rd }}$ ed., pp. 681-688). Rio de Janeiro, Brazil: Editora Interciência.

Toombs, H. A., \& Rixon, A. E. (1959). The use of acids in the preparation of vertebrate fossils. Curator: The MuseumJournal, 2(4), 304-312. 